\section{Listeria monocytogenes contamination in dairy plants: evaluation of Listeria monocy- togenes environmental contam- ination in two cheese-making plants using sheeps milk}

\author{
Michela Ibba, Francesca Cossu, \\ Vincenzo Spanu, Salvatore Virdis, \\ Carlo Spanu, Christian Scarano, \\ Enrico P.L. De Santis
}

Dipartimento di Medicina Veterinaria, Università degli Studi di Sassari, Italy

\begin{abstract}
Listeria monocytogenes harbouring niches established in the processing plant support post-process contamination of dairy products made from pasteurised or thermised milk. The present study investigated $L$. monocytogenes environmental contamination in two sheep's milk cheese-making plants. Persistence of contamination in the area at higher risk was also investigated. During a one-year survey 7 samplings were carried out in each dairy plant, along the production lines of Pecorino Romano and ricotta salata cheese. A total of 613 environmental samples collected from food contact and non-food contact surfaces were analysed according to ISO 11290-1:2005 standard method. Identification of the isolated strains was carried out by polymerase chain reaction. L. monocytogenes prevalence was $23.2 \%$ in dairy A and $13.1 \%$ in dairy B, respectively. The higher prevalence rate was found in the following areas: salting, products washing, packaging, ricotta salata storage and Pecorino Romano ripening rooms. L. monocytogenes was never found in the cheese-making area. The probability of observing samples positive for the presence of $L$. monocytogenes was associated with dairy plant, sampling area and the period of cheese-making $(\mathrm{P}<0.001)$. The greater persistence of contamination over time was observed in the washing, salting, and Pecorino Romano ripening areas. The control dairy products is mainly ascribed to a postprocess contamination originating from the processing environment (Tompkin, 2002; Unnerstad et al., 1996). Contamination is generally associated with the presence of resident strains that colonise specific niches in processing plant environments (Blackman and Frank, 1996). Niches are represented by areas with favorable conditions for $L$. monocytogenes growth and persistence, such as moisture and condenses, low temperatures and high $\mathrm{NaCl}$ concentrations (Tompkin, 2002). Moreover, the ability of $L$. monocytogenes to adhere on surfaces and form biofilms allows the microorganism to adapt and resist against detergents and sanitisers (Chavant et al., 2004; Pan et al., 2006). The evaluation of $L$. monocytogenes environmental contamination is essential, especially in cheese-making plants producing foods able to support $L$. monocytogenes growth or that are exposed to the environment after lethality treatments are applied. (European Commission, 2005; USDA/FSIS, 2006; Health Canada, 2011). In Sardinia milk production and cheese-making are seasonal and gathered during the winter-spring period, which is referred to as cheese-making season. The aim of the present research was to evaluate the prevalence of $L$. monocytogenes environmental contamination over the cheese-making season in two Sardinian sheep's milk cheese-making plants. The relationship between $L$. monocytogenes persistence niches and dairy products contamination during the dairy season was also assessed.
\end{abstract} of persistent environmental contamination relies on the identification of $L$. monocytogenes niches within the processing environment and the prevention of harborage sites formation. The importance of strict cleaning and sanitising procedure in controlling $L$. monocytogenes environmental contamination is confirmed by the lower level of contamination observed after these procedures were correctly implemented.

\section{Introduction}

Raw milk contaminated with Listeria monocytogenes could represent a potential source for the introduction of the pathogen in dairy products processing plant environment. The prevalence of positive raw milk samples ranges between 3.0 and 6.5\% (Vitas et al., 2004; AlTahiri et al., 2008), with estimated most probable concentration of 0.1 colony forming units/mL (Meyer-Broseta et al., 2003). The application of thermisation and pasteurisation processes in sheep milk cheese-making plants results in a 3 to $6 \log$ reduction of the number of viable $L$. monocytogenes cells present in raw milk (ICMSF, 1996; Pearce et al., 2012). Therefore, the presence of $L$. monocytogenes in

\section{Materials and Methods}

Environmental samples were collected from processing areas and equipment in two sheep milk cheese-making plants located in Sardinia. In order to take into account seasonal variations each dairy plant was visited 7 times during the cheese-making season. Three visits
Correspondence: Michela Ibba, Dipartimento di Medicina Veterinaria, Università degli Studi di Sassari, via Vienna 2,07100 , Sassari, Italy. Tel: +39.079 .229454 - Fax: +39.079 .229458 . E-mail:mibba@uniss.it

Key words: Listeria monocytogenes, Environmental contamination, Persistence.

Conflict of interests: the authors declare no potential conflict of interests.

Received for publication: 27 March 2013.

Revision received: 24 April 2013.

Accepted for publication: 24 April 2013

This work is licensed under a Creative Commons Attribution 3.0 License (by-nc 3.0).

(C) Copyright M. Ibba et al., 2013

Licensee PAGEPress, Italy

Italian Journal of Food Safety 2013; 2:e31

doi:10.4081/ijfs.2013.e31

were conducted during the peak of production (January-June), 2 visits during the break in cheese-making production (SeptemberOctober) and the other 2 at the beginning of cheese-making season (NovemberDecember). Overall 613 environmental samples were collected. During each visit environmental samples were collected along production lines of ricotta cheese, Pecorino Romano and in environments shared by these products, such as areas of coagulation, ricotta production, molding, salting, washing, ripening and packaging. Environmental sampling included food contact surfaces (tables, carts, shelves, molds, machinery) and non-food contact surfaces (outer surfaces of equipment, walls, floors and floor drains). Sampling was conducted during processing operation using sterile sponges pre-moistened with neutralising buffer (3M, St. Paul, MN, USA). In order to increase the likelihood of detecting $L$. monocytogenes no delimitation of sampling area was defined. After sampling each sponge was placed into a sterile bag and kept refrigerated until analysis. The detection of $L$. monocytogenes was performed according to standard method ISO 11290-1/A1 (ISO, 2005). In the present study a persistent contamination site was defined as the recovery of $L$. monocytogenes from a defined site, in two or more sampling time during the observation period. All the isolates were identified as $L$. monocytogenes by PCR and major serotype were also detected using primers Imo0737, Imo1118, ORF2819 and ORF2110 (Doumith et al., 2004). Differences in $L$. monocytogenes prevalence between the two cheese-making plants were compared using chi-square test. The probability of recovering $L$. monocytogenes was investigated using logistic regression (Statgraphics 
Plus software ver. 16.0.09). The probability of observing samples positive for $L$. monocytogenes was the binary response variable (presence, absence). The effect of the dairy (A and B), production phase (peak, break and resume of production), production line (Pecorino Romano, ricotta, common line), areas (cheese curdling, whey floating, salting, seasoning Pecorino Romano, ricotta storage, cheese washing, packaging, other), sampling site (shelves, carts, tables, cheeses washing machines, floors, drains, molds, other), type of surface (food contact and non-food contact) were included in the model.

\section{Results}

L. monocytogenes was detected in 109 (17.8\%) out of the 613 collected samples. Overall the prevalence was $23.2 \%$ for dairy A and $13.1 \%$ for dairy B. In dairy A $L$. monocytogenes was detected in 29 (26.4\%) out of 110 food contact surfaces and in 37 (21.1\%) out of 175 non-food contact surfaces. In dairy B $L$. monocytogenes was detected in $15(10.9 \%)$ out of 138 food contact surfaces and in 28 (14.7\%) out of 190 non-food contact surfaces.

$L$. monocytogenes prevalence reported for the two cheese-making plants in the three main production phases are showed in Table 1. In Table 2 is reported the prevalence of $L$. monocytogenes along the production lines of Pecorino Romano, ricotta salata and in the common production areas. The production period influenced $L$. monocytogenes prevalence only for Pecorino Romano's ripening rooms. The probability (odds ratio) to detect $L$. monocytogenes in Pecorino Romano's ripening rooms was ca. 6 times lower in the resume production period as compared to the peak of production and break periods (Table 3). Comparison between the cheese-making plants showed that the probability of contamination was 2 times greater in dairy $A$ than in dairy $\mathrm{B}(\mathrm{P}<0.01)$. The highest rate of contamination was observed for cheese washing rooms (44.5\%), packaging area (36.8\%), salting room (33.3\%), ricotta storage room (25.6\%) and Pecorino Romano ripening area (13.9\%). $L$. monocytogenes was detected in $3.3 \%$ of the samples collected from whey floating area, while, in curdling area the microorganism was never detected. In the areas common to the two main production lines, $L$. monocytogenes prevalence was $5.9 \%$. Logistic regression analysis showed that the probability of detecting $L$. monocytogenes in samples was significantly affected by the following factors: cheese making plant, production phases and production areas $(\mathrm{P}<0.001)$. No significant effect of production line, site and surface type was observed. L. monocytogenes persistent contamination was detected in cheese washing rooms of both cheese-making plants, in the following sites: washing machine, floors and drains. Pecorino Romano production line was characterised by persistent contamination in the ripening rooms (shelves, drains and floors) and salting room (drains). Ricotta salata storage rooms showed persistent contamination of drains and floors. Polymerase chain reaction results on serotyping showed that all the 43 strains isolated from dairy B were serotype 1/2a. On the other hand, dairy A showed a wide strains variability with 17 isolates (25.8\%) belonging to serotype $1 / 2 \mathrm{a}, 27$ (40.9\%) and 22 (33.0\%) to serotypes1/2b and 4b, respectively.

\section{Discussion and Conclusions}

The present study was aimed to investigate the prevalence and the persistence of $L$. monocytogenes environmental contamination in two sheep milk cheese-making plants. The probability of detecting $L$. monocytogenes positive samples was significantly affected by the plants, processing areas and production phases during the cheese-making season $(\mathrm{P}<0.001)$. L. monocytogenes environmental contamination was twice as much in dairy A as compared to dairy B. However, great part of the difference in $L$. monocytogenes prevalence was accountable to contamination observed along the Pecorino Romano production line. Little differences between cheese-

Table 1. Listeria monocytogenes prevalence on surfaces in relation to the period of dairies activity (A, B).

\begin{tabular}{|c|c|c|c|c|c|c|c|c|c|}
\hline \multirow[t]{2}{*}{ Dairy } & \multicolumn{6}{|c|}{$\begin{array}{l}\text { Cheese-making period } \\
\text { Break }^{\circ}\end{array}$} & \multicolumn{3}{|c|}{ Resuming\# } \\
\hline & n & $\mathrm{Lm+}$ & $\%$ & n & $\mathrm{Lm}+$ & $\%$ & n & $\mathrm{Lm+}$ & $\%$ \\
\hline A & 79 & 29 & 36.7 & 76 & 21 & 27.6 & 83 & 16 & 19.3 \\
\hline B & 94 & 30 & 31.9 & 94 & 8 & 8.5 & 111 & 5 & 4.5 \\
\hline Total & 173 & 38 & 34.3 & 170 & 29 & 17.1 & 194 & 21 & 10.8 \\
\hline
\end{tabular}

Lm, Listeria monocytogenes. ${ }^{*}$ Peak of production in January, March, and June; ${ }^{\circ}$ break of production in September and October; ${ }^{*}$ resuming of production in November and December.

Table 2. Listeria monocytogenes prevalence in different areas of the two dairies.

\begin{tabular}{|c|c|c|c|c|c|c|c|c|}
\hline Line/room & $\mathrm{n}$ & $\begin{array}{c}\text { A } \\
\mathrm{Lm}+\end{array}$ & $\%$ & $\mathrm{n}$ & $\begin{array}{c}\text { B } \\
\text { Lm+ }\end{array}$ & $\%$ & P value & Odds ratio \\
\hline $\begin{array}{l}\text { Pecorino Romano } \\
\text { Cheese-making } \\
\text { Ripening }\end{array}$ & $\begin{array}{c}28 \\
102\end{array}$ & $\begin{array}{c}0 \\
20\end{array}$ & $\begin{array}{c}0.0 \\
19.6\end{array}$ & $\begin{array}{l}33 \\
99\end{array}$ & $\begin{array}{l}0 \\
8\end{array}$ & $\begin{array}{l}0.0 \\
8.1\end{array}$ & $<0.05$ & - \\
\hline $\begin{array}{l}\text { Ricotta salata } \\
\text { Ricotta processing } \\
\text { Ricotta storage }\end{array}$ & $\begin{array}{l}42 \\
17\end{array}$ & $\begin{array}{l}1 \\
8\end{array}$ & $\begin{array}{c}2.4 \\
47.1 \\
\end{array}$ & $\begin{array}{l}48 \\
26 \\
\end{array}$ & $\begin{array}{l}2 \\
3 \\
\end{array}$ & $\begin{array}{c}4.2 \\
11.5\end{array}$ & $\begin{array}{c}\text { NS } \\
<0.05\end{array}$ & $\begin{array}{l}0.6 \\
6.8\end{array}$ \\
\hline $\begin{array}{l}\text { Common areas } \\
\text { Product washing } \\
\text { Packaging } \\
\text { Salting } \\
\text { Other } \\
\text { Total }\end{array}$ & $\begin{array}{c}68 \\
7 \\
- \\
21 \\
285\end{array}$ & $\begin{array}{c}30 \\
4 \\
- \\
3 \\
66\end{array}$ & $\begin{array}{c}44.1 \\
57.1 \\
- \\
14.3 \\
23.2\end{array}$ & $\begin{array}{c}42 \\
12 \\
21 \\
47 \\
328\end{array}$ & $\begin{array}{c}19 \\
3 \\
7 \\
1 \\
43\end{array}$ & $\begin{array}{c}45.2 \\
25.0 \\
33.3 \\
2.1 \\
13.1\end{array}$ & $\begin{array}{c}\text { NS } \\
\text { NS } \\
- \\
<0.05 \\
<0.01\end{array}$ & $\begin{array}{c}0.9 \\
4.0 \\
- \\
7.7 \\
2.0\end{array}$ \\
\hline
\end{tabular}

Lm, Listeria monocytogenes; NS, not significant. 
making plants were observed for ricotta salata and common production areas. Environmental conditions, pre-operational sanitation and the adoption of good manufacturing practice reduce the risk of colonization in cheese curdling and whey floating areas (Pilo et al., 2007). Therefore, contamination of the products in these areas should be considered as a sporadic event. Instead, L. monocytogenes prevalence observed in washing, drying and packaging rooms was higher, resulting in an increased risk for products contamination (FSIS, 2010). The higher prevalence could be explained by specific condition observed in these areas, such as low temperatures, high salt concentration, presence of environmental surfaces difficult to clean and sanitise (i.e. wood). Cheese cleaning and ripening rooms are areas shared between Pecorino Romano and ricotta salata, therefore they may represent a potential source of cross-contamination between the two production lines. With regard to the production phases the probability of contamination in ripening rooms was about 6 times lower during the resuming of production as compared to other phases. This could be explained by the effectiveness of cleaning and sanitizing procedures conducted during the break production period. Differences in $L$. monocytogenes prevalence were observed between the two cheese-making plants based on the sampling period. In dairy B a significant decrease in the contamination prevalence was observed in the break and resuming production phases, while in dairy A the reduction was limited. Moreover, in diary A the contamination of food contact surfaces was higher than in dairy B. Dairy A was also characterised by a greater strains variability, with isolates belonging to $L$. monocytogenes lineage I (serotypes $1 / 2 \mathrm{~b}$ and $4 \mathrm{~b}$ ) and II (serotype $1 / 2 a$ ), while in dairy B all strains belonged to lineage II. Persistent contamination was observed in sites with favorable conditions for microorganism survival. In cheese washing machine the increased risk was represented by the presence of organic residues and the poor hygienic design of the equipment which limit the cleaning and sanitization effectiveness. Other sites, such as floors, drains, mainly in salting ripening and storage area, served as niches for L. monocytogenes. Persistent contamination seem to be related to the inability to remove and inactivate strains from niche sites rather than specific strain properties (Carpentier and Cerf, 2011). The regular implementation of environmental sampling programs is strongly recommended in order to monitor the level of $L$. monocytogenes contamination and the presence of persistent harborage sites (trend analysis). The application of strict cleaning and sanitizing procedures is essential in order to prevent on one hand the re-introduction of $L$. monocytogenes into the plant environment and on the other hand the establishment of niches which serve as a potential source of product contamination.

Table 3. Comparison of Listeria monocytogenes prevalence in different areas in the three production periods.

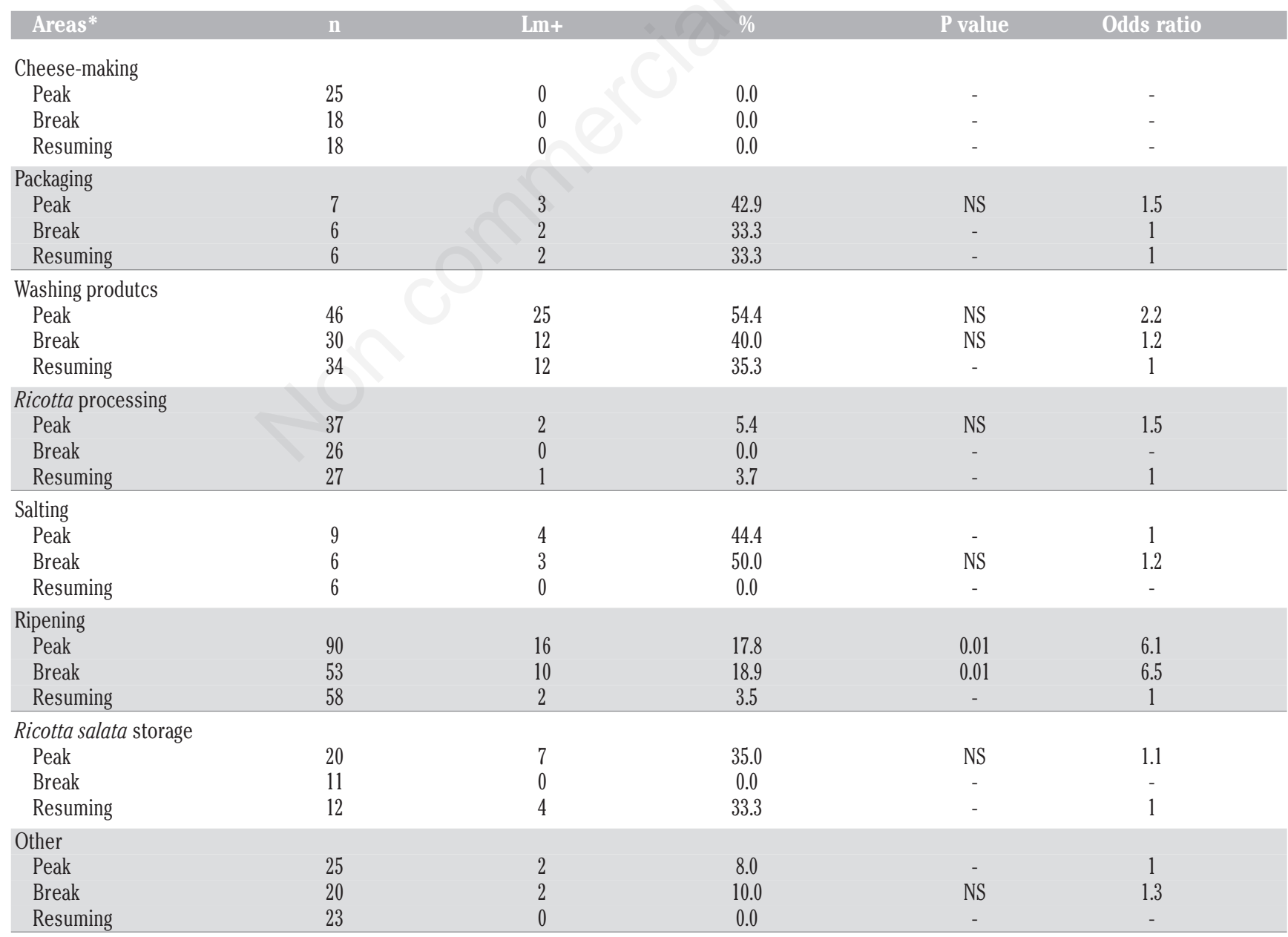

Lm, Listeria monocytogenes; NS, not significant. *Note that peak of production occurred in January, March, and June, break of production in September and October, and resuming of production in November and December. 
Washington, DC, USA. Available from: http://www.fsis.usda.gov/PDF/Comparative _RA_Lm_Report_May2010.pdf

Al-Tahiri R, Omar S, Rewashdeh A, 2008. A study of the occurrence of Listeria species in raw sheep milk. Int $\mathbf{J}$ Dairy Technol 61:347-1.

Blackman IC, Frank JF, 1996. Growth of Listeria monocytogenes as a biofilm on various food-processing surfaces. J Food Protect 59:827-1.

Carpentier B, Cerf 0, 2011. Review. Persistence of Listeria monocytogenes in food industry equipment and premises. Int J Food Microbiol 145:1-8.

Chavant P, Gaillard-Martinie B, Hebraud M, 2004. Antimicrobial effects of sanitizers against planktonic and sessile Listeria monocytogenes cells according to the growth phase. FEMS Microbiol Lett 236:241-8.

Doumith M, Buchrieser C, Glaser P, Jacquet C, Martin P, 2004. Differentiation of the major Listeria monocytogenes serovars by multiplex PCR. J Clin Microbiol 42:381922.

European Commission, 2005. Regulation (EC) of the European Commission of 15 November 2005 on on microbiological criteria for foodstuffs, 2073/2005/EC. In: Official Journal, L 338/1, 22/12/2005.

FSIS, 2010. Comparative risk assessment for Listeria monocytogenes in ready-to-eat meat and poultry deli meats report. Food Safety and Inspection Service ed.,
Health Canada, 2011. Policy on Listeria monocytogenes in ready-to-eat Foods. Food directorate. Health products and food branch. Health Canada ed., Ottawa, Ontario, Canada. Available from: http://www.hc-sc.gc.ca/fn-an/legislation/ pol/policy_listeria_monocytogenes_2011eng.php

ICMSF, 1996. Microorganisms in food: microbiological specifications of food pathogens. Blackie Academic and Professional ed., London, UK.

ISO, 2005. Horizontal method for the detection and enumeration of L. monocytogenes. Part 1: detection method. Amendment 1: modification of the isolation media, of the haemolysis test and inclusion of precision data. ISO norm 11290-1:1996/Amd 1:2005. International Organization for Standardization ed., Geneva, Switzerland. Italiano di Unificazione, Milan, Italy.

Meyer-Broseta S, Diot A, Bastian S, Rivière J, Cerf 0, 2003. Estimation of low bacterial concentration: Listeria monocytogenes in raw-milk. Int J Food Microbiol 80:1-15.

Pan Y, Breidt F Jr, Kathariou S, 2006. Resistance of Listeria monocytogenes biofilms to sanitizing agents in a simulated food processing environment. Appl Environ Microb 72:7711-7.

Pilo AL, Marongiu P, Corgiolu G, Virdis S, Scarano C, De Santis EPL, 2007. Listeria monocytogenes contamination sources in sheep cheese processing plants and strains virulence genes typing. In: Proceeding of the 5th IDF International Symposium on the Challenge to Sheep and Goats Milk Sectors, Alghero, Italy.

Pearce EL, Smythe BW, Crawford RA, Oakley E, Hathaway SC, Shepherd JM, 2012. Pasteurization of milk: the heat inactivation kinetics of milk-borne dairy pathogens under commercial-type conditions of turbulent flow. J Dairy Sci 95:20-5.

Tompkin RB, 2002. Control of Listeria monocytogenes in the food-processing environment. J Food Protect 65:709-15.

Unnerstad H, Bannerman E, Bille J, Danielssontham ML, Waak E, Tham W, 1996. Prolonged contamination of a dairy with Listeria monocytogenes. Neth Milk Dairy J 50:493-9.

USDA/FSIS, 2006. Compliance guidelines to control Listeria monocytogenes in postlethality exposed ready-to-eat meat and poultry products. US Department of Agriculture ed., Washington, DC, USA. Available form: http://www.fsis.usda.gov/ oppde/rdad/FRPubs/97 - 013 F/L M Rule_Compliance_Guidelines_May_2006. pdf

Vitas AI, Aguado V, Garcia-Jalon I, 2004. Occurrence of Listeria monocytogenes in fresh and processed foods in Navarra (Spain). Int J Food Microbiol 90:349-6. 